\title{
Dietary fatty acid composition during pregnancy and lactation in the rat programs growth and glucose metabolism in the offspring
}

\author{
M. Siemelink ${ }^{1}$, A. Verhoef ${ }^{1}$, J. A. M. A. Dormans ${ }^{2}$, P. N. Span ${ }^{3}$, A. H. Piersma ${ }^{1}$ \\ ${ }^{1}$ Laboratory for Health Effects Research, ${ }^{2}$ Laboratory for Pathology and Immunobiology, \\ National Institute of Public Health and the Environment, Bilthoven, the Netherlands \\ ${ }^{3}$ Department of Chemical Endocrinology, University Medical Centre Nijmegen, Nijmegen, the Netherlands
}

\begin{abstract}
Aims/hypothesis. We investigated of the effects of fatty acid composition of the maternal diet on fetal and postnatal growth, morphology of the pancreas and glucose metabolism and muscle hexosamine concentrations in the adult offspring of rats.

Methods. High-fat diets enriched with either saturated or unsaturated fatty acids were fed to female adult rats 2 weeks before mating until the end of the weaning period. After weaning, the offspring was maintained on a diet with a balanced fatty acid content. At 3 months of age, pancreatic Langerhans islet size and number were assessed by morphometric analysis and oral glucose tolerance tests (OGTT) were carried out. Results. The unsaturated fatty acid diet showed lower birth weight and reduced postnatal weight gain. Furthermore, this group showed increased pancreatic islet numbers without affected glucose tolerance at the age
\end{abstract}

of 12 weeks. The offspring of the saturated fatty acid diet group showed a reduced number of large pancreatic islets. Moreover, a faster and higher insulin response was observed after an oral glucose load in these animals. Muscle hexosamine concentrations were not different between groups.

Conclusion/interpretation. Maternal diets enriched with either saturated fatty acids or unsaturated fatty acids had opposite effects on pancreatic islet development in rat offspring, with consequences for the insulin response at 12 weeks of age. Therefore, maternal dietary fatty acid composition plays a role in programming growth, pancreatic development and glucose metabolism in the offspring. [Diabetologia (2002) 45:1397-1403]

Keywords Prenatal programming, glucose tolerance, endocrine pancreas, fatty acids, maternal diet, fetal growth, insulin.
The programming influence of nutritional conditions in utero on fetal growth and on the susceptibility to disease in adulthood is now widely recognized. Another study $[1,2,3]$ showed an inverse relation between birth weight and the risk of coronary heart disease in later life in several large epidemiologic stud-

Received: 25 March 2002 / Revised: 24 May 2002

Published online: 5 September 2002

C) Springer-Verlag 2002

Corresponding author: Dr. A. H. Piersma, Laboratory for Health Effects Research, National Institute of Public Health and the Environment, P.O. Box 1, 3720 BA Bilthoven, the Netherlands. E-mail: ah.piersma@rivm.nl

Abbreviations: CON, Control; UFA, unsaturated fatty acid; SFA, saturated fatty acid; LP, low protein. ies. Epidemiologic studies have shown a relation between size at birth and the risk of developing insulin resistance or diabetes in adulthood [4, 5, 6, 7]. It was hypothesized that poor maternal nutrition causes reduced fetal growth and glucose intolerance later in life. A low protein diet in rat pregnancy has been shown to yield low birth weight progeny which are unable to regain an appropriate insulin secretory response to a glucose challenge even when given a normal protein diet throughout adult life [8]. Growth retarded newborn infants have been shown to have reduced numbers of beta cells and a reduced insulin secretion [9]. Moreover, a reduction in the number and size of pancreatic islet cells and a reduced vascularization of the endocrine pancreas has been shown in animal studies, even after a normal diet was given 
post-natally $[8,10,11,12,13,14]$. In rats, an effect of free fatty acids on the hexosamine pathway, preceding the onset of insulin resistance, has been shown [15]. The concentrations of the end products of this pathway, i.e. UDP-N-acetyl-glucosamine (UDP-Gl $\mathrm{NA}_{\mathrm{c}}$ ) and UDP-N-acetyl-galactosamine (UDP-GalNA ${ }_{c}$ ), are highly correlated with the degree of insulin resistance [15]. Others have also shown that incubation of multiple insulin-sensitive rat and human tissues with glucosamine to generate increased concentrations of $\mathrm{UDP}-\mathrm{Gl}_{\mathrm{c}} \mathrm{NA}_{\mathrm{c}}$ induces insulin resistance $[16,17,18$, 19, 20]. Streptozotocin-induced diabetes and sustained hyperglycaemia in normal rats also increase total UDP-hexosamine content in muscle tissue [21].

The epidemic of obesity and diabetes in developing countries could be at least partly explained by the discrepancy between prenatal malnutrition and postnatal food abundance [22, 23, 24]. In western societies, these diseases also show an increasing incidence whereas undernutrition in pregnancy is less prevalent. The high fat intake and the shift between fat sources and their different fatty acid composition could play a role here. The Dutch food consumption survey has shown a shift in fatty acid intake in recent decades [25]. This study investigates the effects of maternal dietary fatty acid composition on fetal and postnatal growth in the rat. In addition, the morphology of the pancreas and glucose tolerance were studied in the adult offspring. Furthermore, effects on muscular hexosamine concentrations were assessed. We used diets with a fatty acid composition reflecting current dietary choices or recommendations: an enriched saturated fatty acid (SFA) diet based on coconut oil, and a diet rich in unsaturated fatty acids (UFA) based on menhaden fish oil, respectively. Contrary to other studies, these diets were given throughout pregnancy and weaning to cover the continued growth and development of the pancreas in the rat during the early postnatal period [24].

\section{Materials and methods}

Study design. All animal experiments were approved by the Dutch Animal Ethics Committee and the principles of laboratory animal care were followed. We purchased nulliparous rats of the Cpb-WU strain at 9 weeks of age from Harlan Nederland (Horst, The Netherlands). The female rats were caged individually with free access to water. The room was maintained at a constant temperature $\left(22^{\circ} \mathrm{C}\right)$ with a 12 -h light to dark cycle. All rats were fed standard laboratory chow (RMH-GS) for two weeks to acclimatize. The rats were then randomly assigned to the experimental diets at 24 animals per group and fed for at least 2 weeks prior to mating and during pregnancy and weaning. All diets contained around $18 \%$ fat (w/w). The major oil sources in the diets were coconut oil in the SFA diet, menhaden fish oil in the UFA diet and soy oil in the control $(\mathrm{CON})$ diet (Table 1). All diets were semi-synthetic, isocaloric and pelleted and were fed ad libitum to the rats. The diets were stored at $-20^{\circ} \mathrm{C}$ in small portion bags to minimize oxidation.
Table 1. Composition of the experimental diets

\begin{tabular}{lccc}
\hline G/100 g diet & CON diet & UFA diet & SFA diet \\
\hline Ingredients: & & & \\
Casein & 15.8 & 15.5 & 15.4 \\
L-cystein & 0.3 & 0.3 & 0.3 \\
Wheat starch & 42.5 & 44.5 & 43.3 \\
Cellulose & 5 & 5 & 5 \\
Choline bitartrate & 0.25 & 0.25 & 0.25 \\
Ain93G minerals & 3.09 & 3.09 & 3.09 \\
KH$_{2} P_{4}$ & - & - & - \\
Ain93 vitamins & 1.1 & 1.1 & 1.1 \\
Soybean oil & 18.4 & - & - \\
Coconut oil & - & - & 17.4 \\
Safflower oil & - & - & 1 \\
Menhaden fish oil & - & 18.1 & - \\
Energy (kcal/100 g) & 399 & 403 & 400 \\
\hline
\end{tabular}

Freshly thawed portions were offered to the rats daily. The peroxide level of the experimental diets was measured after 3 months of storage and after $24 \mathrm{~h}$ at room temperature.

Experimental oils were purchased from ICN Biochemicals, Cleveland, Ohio, USA. The diets were produced by TNO Nutrition, Zeist, the Netherlands, where all dietary analyses were carried out. Body weight and food intake were monitored at least weekly and food intake was measured by weighing the pellets in the feed containers. Per group eight animals were killed at pregnancy day 21 to study fetal development and fetal body weight and placental weight were measured at gestational day 21 . In addition, the number of fetuses, corpora lutea and resorptions per dam were assessed. The remaining animals were allowed to litter. After parturition, litter size was culled to eight pups and the pups were weighed the day on which the litter was found; this day was defined as postnatal day 1 . The average body weight of the pups per litter per sex was measured weekly. Survival rate was defined as the number of live pups at weaning divided by the number of live pups at birth. At weaning (age 3 weeks), rats were individually marked and housed according to sex. After weaning, the dams were killed and all offspring were fed the control diet. At the age of 12 weeks, an OGTT was carried out and the organs were processed for histopathology.

Oral glucose tolerance test. At age 12 weeks, offspring rats were fasted overnight, and glucose ( $2 \mathrm{~g}$ per $\mathrm{kg}$ body weight) was administered by oral gavage between 8.30 a.m. and 10 a.m.. Blood was collected in heparinized cups (Microvette CB300, Sarstedt, Germany) by the tail incision method at 10 min before and at 5, 10, 20, 30 and 50 min after glucose administration. Blood samples were centrifuged immediately and plasma was stored at $-80^{\circ} \mathrm{C}$. Glucose concentration was measured by a glucose oxidase system (Unimate 5 GLUC HK, Roche, Mannheim, Germany), insulin concentration was measured by a RAT insulin ELISA-kit (Mercodia, Uppsala, Sweden). Both analyses were done within 2 months after storage.

Histologic analysis of internal organs. For histological examination $5 \mu \mathrm{m}$ paraplast sections of the pancreas, adrenals, heart, kidney, liver, pituitary, spleen and thymus were cut and stained with hematoxylin and eosin (HE). For morphometry of the pancreas the number and surface area of the Langerhans islets were measured in one randomly chosen complete longitudinal section per pancreas, using the analySIS soft imaging system (SIS, Münster, Germany). Each section covered at least $100 \mathrm{~mm}^{2}$ and eight animals were analysed per diet group. The 
islets were arbitrarily divided into small and large islets $\left(>0.03 \mathrm{~mm}^{2}\right)$.

UDP-hexosamine metabolites content in rat muscle. Muscle tissue was obtained from the m.adductor magnus to measure UDP-hexosamine metabolites content. Tissues were homogenized with homogenization buffer in a dismembrator using liquid nitrogen. After centrifugation at $60000 \mathrm{~g}$ for $15 \mathrm{~min}$ at $4^{\circ} \mathrm{C}, 1600 \mathrm{pmol}$ of UDP-mannose and $25 \mathrm{pmol}$ of UDP-xylose were added to the supernatant as internal standards. The samples were deproteinized and diluted with $\mathrm{KH}_{2} \mathrm{PO}_{4}$ and applied to solid-phase extraction columns. After the columns were washed (with $\mathrm{KH}_{2} \mathrm{PO}_{4}$ solutions differing in molarity and $\mathrm{pH}$ ), the UDP-sugars were eluted with $\mathrm{KH}_{2} \mathrm{PO}_{4}$. UDP-sugars were separated and quantified by HPLC and ultraviolet detection (at $262 \mathrm{~nm})[26]$.

Statistical analysis. The data of each group was compared to the CON group data. Data is reported as means \pm SEM unless stated otherwise. The data were analysed using a one-way analysis of variance (ANOVA) followed by a two-tailed Dunnett's test. A $p$ value of less than 0.05 was considered to imply a statistically significant difference.

\section{Results}

Diet. The protein content of the diets was 15.4 to $15.8 \%$ and the fat content was around $18 \mathrm{~g}$ per $100 \mathrm{~g}$ diet (Table 1). Carbohydrate and energy contents of the different diets were comparable and the fatty acid composition of the diets is given (Table 2). The UFA diet was high in the n-3 polyunsaturated fatty acids eicosapentaenoic acid (EPA) and docosahexanoic acid (DHA), $11.7 \%$ and $13.1 \%$ of total fatty acids respectively. The SFA diet was high in the short-chain saturated fatty acids lauric acid $(42.3 \%)$ and myristic acid $(17.1 \%)$. The peroxide level of the diets after 3 months of storage at $-20^{\circ} \mathrm{C}$ was $2.4 \mathrm{mmol} \mathrm{O} / \mathrm{kg}$ for the $\mathrm{CON}$ diet, $6.6 \mathrm{mmol} \mathrm{O} / \mathrm{kg}$ for the UFA group and $5.8 \mathrm{mmol} \mathrm{O} / \mathrm{kg}$ for the SFA group.

Maternal growth and food intake. After the first week of the 2-week premating period, in which the animals became accustomed to the experimental diet, the body weight gain in the UFA group was lower than in the CON group $(2.8 \pm 1.1 \mathrm{~g}$ vs $9.3 \pm 2.5 \mathrm{~g}$ ) (Table 3$)$. This was also observed in the pregnancy period: animals of the UFA group gained $116.7 \pm 4.0 \mathrm{~g}$ in body weight whereas animals of the CON group had a body weight gain of $135.2 \pm 4.5 \mathrm{~g}$. Daily food intake during pregnancy is given (Fig. 1). Total food consumption during pregnancy was lower in the UFA group compared to the CON group (339.4 g vs $366.4 \mathrm{~g} ; n=16, p<0.05$ ). Throughout the lactation period, dams which were fed the UFA diet had a lower food intake compared to dams of the CON group (Fig. 2).

Fetal and placental weight. Fetal body weights and placental weights of the experimental groups did not differ statistically from the CON group (Fig. 3A, B).

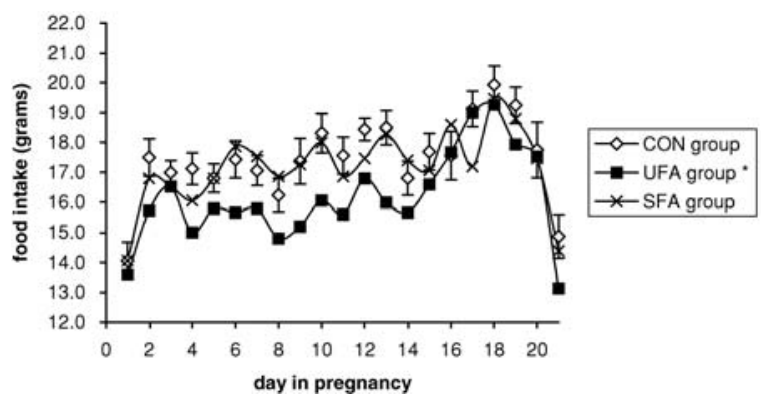

Fig. 1. Absolute daily food intake of mothers fed different diets during pregnancy; $n=16 ; * p<0.05$ compared to CON group. Means \pm SEM given for the control group

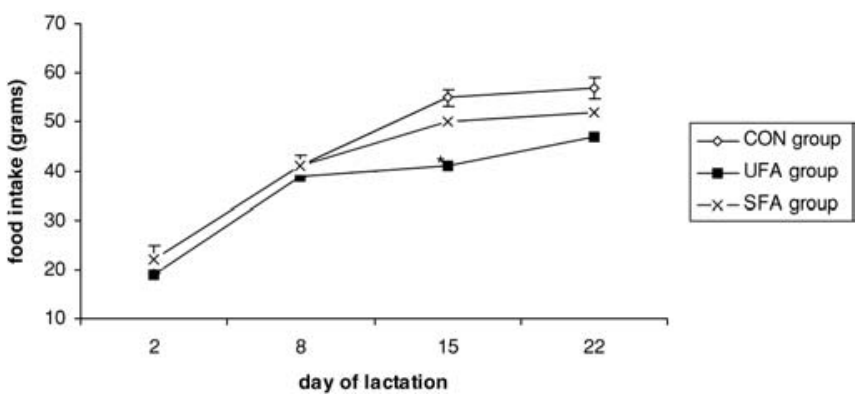

Fig. 2. Absolute daily food intake during lactation of mothers fed different diets; $n=8 ; * p<0.05$ compared to $\mathrm{CON}$ group. Means \pm SEM given for the CON group

Table 2. Analysis of fatty acid of the experimental diets (expressed as percentage of total fatty acids)

\begin{tabular}{llccc}
\hline fatty acid & Trivial name & $\begin{array}{l}\text { CON } \\
\text { diet }\end{array}$ & $\begin{array}{l}\text { UFA } \\
\text { diet }\end{array}$ & $\begin{array}{l}\text { SFA } \\
\text { oil } \\
\text { diet }\end{array}$ \\
\hline C8:0 & caprylic acid & - & - & 5.6 \\
C10:0 & capric acid & - & - & 4.8 \\
C12:0 & lauric acid & 0.1 & 0.2 & 42.3 \\
C14:0 & myristic acid & 11 & 6.9 & 17.1 \\
C16:0 & palmitic acid & - & 17.9 & 10.3 \\
C16:1 (n-7) & palmitoleic acid & 0.2 & 9.2 & 0.1 \\
C17:0 & & 0.1 & 1.8 & 0.1 \\
C18:0 & stearic acid & 4.5 & 3.3 & 4.7 \\
C18:1 (n-9) & oleic acid & 23.1 & 13 & 7.2 \\
C18:2(n-6) & linoleic acid & 51.4 & 2.1 & 6.8 \\
C18:3(n-3) & linolenic acid & 5.8 & 3.0 & 0.3 \\
C20:0 & arachidic acid & 0.4 & 0.3 & - \\
C20:1 (n-9) & eicosanoic acid & 0.1 & 0.6 & - \\
C20:2(n-6) & & - & 0.3 & - \\
C20:3(n-3) & & - & 11.7 & - \\
C20:3(n-6) & dihomo- $\gamma$-linolenic acid & - & 0.2 & - \\
C20:4(n-6) & arachidonic acid & - & 0.7 & - \\
C20:5 (n-3) & eicosapentaenoic acid & - & 11.7 & - \\
C22:0 & behenic acid & 0.3 & 0.2 & - \\
C22:4 (n-6) & adrenic acid & - & 0.2 & - \\
C22:5(n-6) & osbond acid & - & 2.4 & - \\
C22:6(n-3) & docosahexaenoic acid & - & 13.1 & - \\
C24:1 (n-9) & tetracosenoic acid & - & 0.4 & - \\
Not identified & & 3.0 & 0.8 & 0.7 \\
\hline & & & & \\
\hline & & & &
\end{tabular}


Table 3. Body weight gain per interval (grams; means \pm SEM) in female rats, before and during pregnancy, when fed the experimental diets

\begin{tabular}{lccc}
\hline Body weight gain & CON group & UFA group & SFA group \\
\hline Premating: & $N=24$ & $n=24$ & $n=24$ \\
Week 1 & $9.3 \pm 2.5$ & $2.8 \pm 1.1^{\mathrm{a}}$ & $11.0 \pm 2.0$ \\
Week 2 & $7.6 \pm 1.3$ & $7.1 \pm 1.2$ & $3.7 \pm 1.2$ \\
Pregnancy: & $n=16$ & $n=16$ & $n=16$ \\
Day 1-6 & $33.9 \pm 1.2$ & $29.3 \pm 1.3$ & $33.1 \pm 1.5$ \\
Day 7-11 & $21.5 \pm 0.8$ & $19.2 \pm 1.4$ & $20.9 \pm 1.3$ \\
Day 12-16 & $24.9 \pm 1.4$ & $21.5 \pm 1.6$ & $26.2 \pm 1.3$ \\
Day 17-21 & $54.9 \pm 2.9$ & $46.7 \pm 1.9 \mathrm{a}$ & $54.1 \pm 2.7$ \\
Day 1-21 & $135.2 \pm 4.5$ & $116.7 \pm 4.0^{\mathrm{a}}$ & $134.2 \pm 4.3$ \\
\hline
\end{tabular}

${ }^{a} p<0.05$ compared to $\mathrm{CON}$ group

Table 4. Maternal characteristics at gestational day $21(n=8)$

\begin{tabular}{llll}
\hline & Corpora lutea & Resorptions & $\begin{array}{l}\text { Average number } \\
\text { of fetuses }\end{array}$ \\
\hline CON group & $14.5 \pm 0.5$ & $0.4 \pm 0.2$ & $12.0 \pm 1.1$ \\
UFA group & $13.0 \pm 5.6$ & $1.8 \pm 0.6^{\mathrm{a}}$ & $10.5 \pm 0.8$ \\
SFA group & $14.6 \pm 0.7$ & $1.3 \pm 0.5$ & $12.0 \pm 1.2$ \\
\hline
\end{tabular}

Data are expressed as means \pm SEM per dam

The offspring. The number of corpora lutea, resorptions and fetuses at gestational day 21 and the litter size at birth of the remaining dams is shown (Tables 4, 5). The UFA group had increased resorptions and tended to have less fetuses than the other groups at necropsy at gestation day 21 . In addition, at birth, the litter size of this diet group was lower compared to the control group ( $7.8 \pm 2.7$ vs $12.1 \pm 4.3$ pups respectively). In the UFA and the SFA groups, the incidence of dead pups in the first 3 weeks of life was higher compared to the control group. These cases occurred in several litters within each group (5 and 3 litters respectively, Tables 4, 5). Male offspring of mothers in the UFA group had a lower body weight from birth until 12 weeks of age, compared to male pups of the CON group (Table 6). Male pups of mothers fed the SFA diet weighed less at 7 and 14 days of age and females showed similar weight patterns.
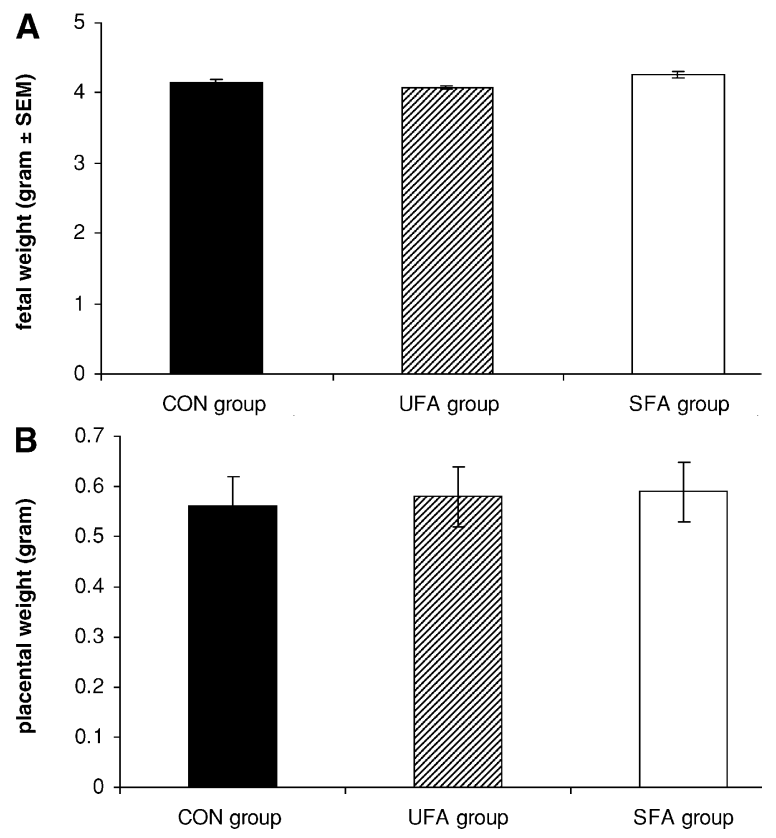

Fig. 3A, B. A Weight of fetuses (males and females) at gestational age 21 days (means \pm SEM in control group: $n=96$, UFA group: $n=83$, SFA group: $n=85$ ). B Placental weight of fetuses (males and females, means \pm SEM) of gestational age 21 days (CON group: $n=96$, UFA group: $n=83$, SFA group: $n=85$ )

Oral glucose tolerance. The fasting insulin concentration tended to be slightly increased in the SFA group, but was not significantly different (Fig. 4). After an oral glucose load, the insulin level rose to statistically higher concentrations in the SFA group compared to the CON group up to $10 \mathrm{~min}$ after the load (mean $760.2 \mathrm{pmol} / \mathrm{l}$ compared to $409.8 \mathrm{pmol} / \mathrm{l}$ in the $\mathrm{CON}$ group, Fig. 4). In addition, the peak response occurred earlier in the SFA group than in the CON group. No difference in the fasting glucose concentration could be found between the male offspring of different groups (Fig. 5). The glucose concentration was lower at $30 \mathrm{~min}$ after the glucose load in the SFA group compared to the CON group (Fig. 5).

Hexosamine pathway intermediates in rat muscle. The results of measurements of metabolites of the hexosamine pathway are given (Table 7). No significant dif-

Table 5. Litter characteristics at birth

\begin{tabular}{|c|c|c|c|c|}
\hline & $\begin{array}{l}\text { Average number of live pups per } \\
\text { dam at birth (mean } \pm \text { SEM) }\end{array}$ & $\begin{array}{l}\text { Number of dead pups } \\
\text { before age } 3 \text { weeks }{ }^{b}\end{array}$ & $\begin{array}{l}\text { No. of litters } \\
\text { with dead pups }\end{array}$ & Survival rate $(\%)$ \\
\hline CON group & $12.1 \pm 4.3(n=9)$ & 0 & 0 & 100 \\
\hline SFA group & $11.8 \pm 3.9(n=10)$ & 11 & 3 & 86 \\
\hline
\end{tabular}

a $p<0.05$ compared to CON group

${ }^{b}$ Number of nests culled to eight and number of pups culled to eight per nest after birth 
Table 6. Body weight (grams; means \pm SEM) in male offspring fed different diets in utero and during weaning

\begin{tabular}{lclc}
\hline Male offspring & $\begin{array}{l}\text { CON } \\
\text { group }\end{array}$ & $\begin{array}{l}\text { UFA } \\
\text { group }\end{array}$ & $\begin{array}{l}\text { SFA } \\
\text { group }\end{array}$ \\
\hline Number of pups week 4-12 & 45 & 32 & 34 \\
Day 1 & $7.3 \pm 0.1$ & $6.7 \pm 0.1^{\mathrm{a}}$ & $7.1 \pm 0.1$ \\
Day 7 & $19.2 \pm 0.3$ & $16.7 \pm 0.4^{\mathrm{a}}$ & $17.8 \pm 0.3^{\mathrm{a}}$ \\
Day 14 & $38.8 \pm 0.5$ & $32.2 \pm 0.5^{\mathrm{a}}$ & $35.8 \pm 1.0^{\mathrm{a}}$ \\
Day 21 & $60.8 \pm 0.6$ & $49.8 \pm 1.1^{\mathrm{a}}$ & $58.2 \pm 0.9$ \\
Week 4 & $96 \pm 1.0$ & $83 \pm 3.0^{\mathrm{a}}$ & $92 \pm 5.0$ \\
Week 5 & $143 \pm 1.2$ & $129 \pm 1.8^{\mathrm{a}}$ & $139 \pm 1.4$ \\
Week 6 & $197 \pm 1.9$ & $182 \pm 3.1^{\mathrm{a}}$ & $192 \pm 2.0$ \\
Week 7 & $250 \pm 2.3$ & $231 \pm 2.6^{\mathrm{a}}$ & $246 \pm 2.8$ \\
Week 8 & $298 \pm 2.7$ & $283 \pm 3.2^{\mathrm{a}}$ & $291 \pm 3.3$ \\
Week 9 & $340 \pm 2.8$ & $322 \pm 3.4^{\mathrm{a}}$ & $328 \pm 4.0$ \\
Week 10 & $374 \pm 3.2$ & $349 \pm 4.0^{\mathrm{a}}$ & $359 \pm 4.4$ \\
Week 11 & $400 \pm 3.5$ & $380 \pm 4.6^{\mathrm{a}}$ & $386 \pm 4.3$ \\
Week 12 & $421 \pm 4.2$ & $399 \pm 5.3^{\mathrm{a}}$ & $404 \pm 4.5$ \\
\hline
\end{tabular}

${ }^{a} p<0.05$ compared to $\mathrm{CON}$ group

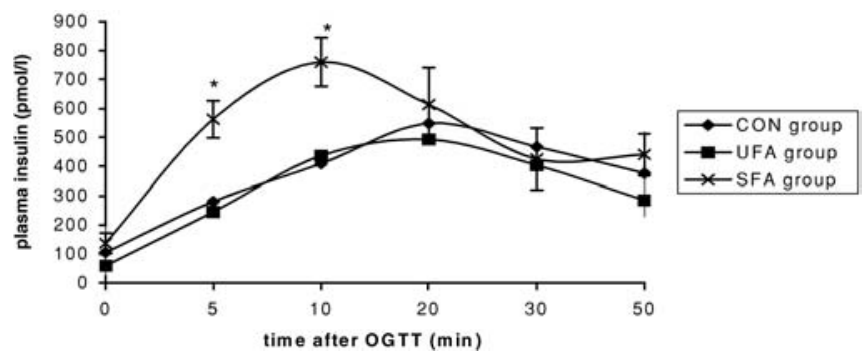

Fig. 4. Plasma insulin response after oral glucose load in male offspring, 12 weeks of age, fed different diets in utero and during weaning; $n=8 ; * p<0.05$ compared to CON group (means \pm SEM)

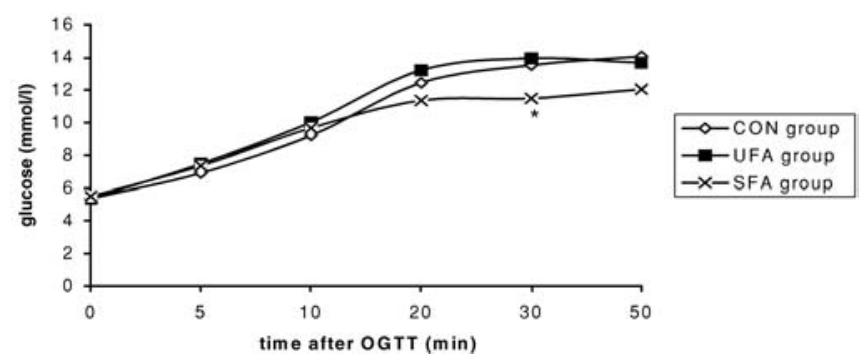

Fig. 5. Plasma glucose response after oral glucose load in male offspring, 12 weeks of age, fed different diets in utero and during weaning; $n=8 ; * p<0.05$ compared to CON group, means \pm SEM

ferences were found in the experimental groups as compared to the $\mathrm{CON}$ group.

Histopathology. In the UFA group, the number of pancreatic islets was increased over that in the CON group, whereas the total volume estimate was unchanged. The sample size seemed too small for the apparently large islet number effect to become significant. In the SFA group, the number and volume esti-
Table 7. Metabolites of the hexosamine pathway in rat muscle

\begin{tabular}{lllllr}
\hline \multicolumn{5}{c}{ UDP nmol/ml homogenate } \\
\cline { 2 - 6 } & $n$ & Gal & GalNAc & Glc & GlcNAC \\
\hline CON group & 4 & $1.16 \pm 0.2$ & $4.49 \pm 0.4$ & $1.03 \pm 0.5$ & $9.99 \pm 1.0$ \\
UFA group & 4 & $1.14 \pm 0.2$ & $4.88 \pm 0.3$ & $0.34 \pm 0.1$ & $10.45 \pm 0.3$ \\
SFA group & 4 & $0.96 \pm 0.2$ & $4.33 \pm 0.3$ & not detectable & $8.62 \pm 0.8$
\end{tabular}

Gal, UDP-galactose; GalNAc, UDP-N-acetyl-galactosamine; Glc, UDP-glucose; GlcNAC, UDP-N-acetyl-glucosamine. Data are expressed as means \pm SEM

Table 8. Volume and number of pancreatic islets in animals, 12 weeks of age, fed different diets in utero and during weaning

\begin{tabular}{llrl}
\hline & $\begin{array}{l}\text { Volume } \\
\text { density } \\
\text { of islets }\end{array}$ & $\begin{array}{c}n \text { islets / } \\
100 \mathrm{~mm}^{2}\end{array}$ & $\begin{array}{l}n \text { islets } \\
>0.03 \mathrm{~mm}^{2} / \\
100 \mathrm{~mm}^{2}\end{array}$ \\
\hline CON group & $1.39 \pm 0.1$ & $69 \pm 4.9$ & $12.0 \pm 1.1$ \\
UFA group & $1.24 \pm 0.2$ & $107 \pm 8.5$ & $\begin{array}{r}10.4 \pm 1.7 \\
6.5 \pm 1.2^{\mathrm{a}}\end{array}$ \\
\hline SFA group & $1.09 \pm 0.1$ & $76 \pm 6.0$ & \\
\hline
\end{tabular}

a $p<0.05$ compared to $\mathrm{CON}$ group

$n=8$. Data are expressed as means \pm SEM

mates of the islets were not different from the CON group (Table 8), but the number of large islets was decreased. The relative weight of the pancreas as well as of all the other organs examined were not different between the experimental groups and the CON group.

\section{Discussion}

This study confirms and extends data showing that maternal nutrition has permanent effects on postnatal growth and on pancreatic structure and function in rat offspring in adult age. Our data show that maternal dietary fatty acid balance does influence the development of the offspring. This becomes apparent firstly in the body weight development of the offspring. Whereas fetal weights at gestation day 21 do not show statistical differences between the groups, after birth both the SFA and UFA groups show reduced pup growth, resulting in permanently reduced body weights in the UFA group. The observed effects of dietary fatty acid balance are probably not due to nutritional deficiencies, as the diets contained the minimum essential fatty acid concentrations. The finding of smaller pups in the UFA group coincides with the lower food intake and weight gain of the mothers. During the last 3 days of gestation the fetal endocrine pancreas develops quickly and fetal insulin regulates fetal metabolism. We cannot exclude that reduced maternal food intake could have retarded this development. It is not clear whether the $7 \%$ reduction in food intake in pregnancy observed in the UFA group could have affected post- 
natal growth. This reduction is probably attributable to the 'fishy' taste of the feed. Caloric restriction studies have needed a far higher $(30 \%$ or $50 \%)$ caloric reduction for clear effects to be observed [27]. Moreover, the SFA group showed normal food intake during pregnancy and lactation, but had a weight gain profile similar to the UFA group. The normal placental weights in the SFA and UFA groups is a further indication that nutrition in the former two groups was adequate.

The number of live pups per nest was decreased in the UFA group. The non-significant trends towards lower corpora lutea numbers and higher resorption numbers in these animals have certainly contributed to this finding. The decreased survival rates in all experimental groups was not expected on the basis of the observed pup weights at postnatal day 1 . We found no clinical signs for possible causative factors such as deficient suckling, reduced maternal care or maternal stress followed by cannibalism of less thriving pups.

Morphometric examination of pancreatic tissue in the offspring at 12 weeks of age showed remarkable differences between the various diet groups. The tendency for decreased total islet volume and the decreased numbers of large islets in the SFA group is consistent with earlier studies with low protein diets $[8,28,29,30]$. They showed that impaired islet development at weaning is not fully compensated by islet growth and neogenesis later in life. In contrast, the UFA group tended to have an increased total number of islets in the absence of a lower number of larger islets. This finding suggests that the number of small islets was larger in this group, indicating an increase in islet neogenesis. Thus, a diet enriched in saturated fatty acids seemed to inhibit islet development, whereas a diet enriched in unsaturated fatty acids had the opposite effect, promoting the development of pancreatic islets.

The anatomy of the adult pancreas depends on a complex sequence of prenatal and post-natal developmental processes $[31,32]$. During weaning, the balance between beta-cell apoptosis and cellular proliferation determines the transformation of the fetal pancreas into its post-weaning state. Concomitantly, its responsivity to insulin greatly increases during weaning. After weaning, the plasticity and turnover of islets and of beta cells are diminished and this emphasizes the importance of adequate prenatal and early postnatal pancreatic development $[33,34]$. Both low protein diet and caloric restriction studies in animals have been shown to influence pancreatic development [27]. In addition, the effects of fatty acid balance changes studied here are directly relevant to human dietary habits in western societies, where fast food is increasingly popular. The diets in our study contained $18 \%$ (w/w) fat, which was considered a workable compromise between the normal rat diet containing $5 \%(\mathrm{w} / \mathrm{w})$ fat and the human with up to $35 \%$ of energy derived from fat. The Dutch nutrition surveys have actually shown remarkable changes in fatty acid intakes during the last decades [25]. It is tempting to suggest that the emerging global epidemic of obesity and diabetes could be partly explained by nutritionally caused suboptimal pancreatic development. The observed effects shown here of dietary fatty acid balance during pregnancy and weaning on offspring pancreatic anatomy support this hypothesis.

The functionality of the pancreatic beta-cell compartment, tested with an OGTT in the offspring at 12 weeks of age showed an increased insulin response in the SFA group. The increased number of islets in the UFA group did not result in an observed change in insulin response. These findings confirm that the insulin response cannot be related readily to pancreatic morphology [27, 35, 36]. Cellular insulin content as well as the magnitude of the cellular response to glucose could differ greatly among islets and among beta cells. In addition, the peripheral response to insulin plays an important role. We have not seen changes in muscular glucosamine patterns that would suggest differences in peripheral glucose utilization between groups at 12 weeks of age. However, differences could develop with ageing. On the other hand, hexosamine might not be a good indicator of insulin resistance on a high-fat diet, new findings indicate that muscle resistance is related to muscle lipid deposition and consequently high diacylglycerol content and PKC activation on such diets [37]. Our findings indicate that the nutritional fatty acid balance during development programs pancreatic responsivity, observable as early as at 12 weeks of age. Such studies could lead to nutritional recommendations for pregnant women which could contribute to the prevention of diabetes in their offspring.

Acknowledgements. The authors are grateful for expert technical assistance of H.H. Loendersloot, S.G.P. de Waal-Jacobs, G. Pesman, C.W. Schot, P. Reulen, A. de Liefde, H.W. Verharen, P.K. Beekhof, R. van Loenen and C.G.J. Sweep.

\section{References}

1. Barker DJ, Osmond C, Simmonds SJ, Wield GA (1993) The relation of small head circumference and thinness at birth to death from cardiovascular disease in adult life. BMJ 306: 422-426

2. Barker DJP (1995) Fetal origins of coronary heart disease. BMJ 311: 171

3. Barker DJ (1996) The fetal origins of hypertension. J Hypertens Suppl 14: S117-S120

4. Barker DJ, Hales CN, Fall CH, Osmond C, Phipps K, Clark PM (1993) Type II (non-insulin-dependent) diabetes mellitus, hypertension and hyperlipidaemia (syndrome $\mathrm{X}$ ): relation to reduced fetal growth. Diabetologia 36: 62-67

5. Dahri S, Reusens B, Remacle C, Hoet JJ (1995) Nutritional influences on pancreatic development and potential links with non insulin dependent diabetes. Proc Nutr Soc 54: 345-356 
6. Phillips DI, Barker DJ, Hales CN, Hirst S, Osmond C (1994) Thinness at birth and insulin resistance in adult life. Diabetologia 37: 150-154

7. Phillips DI, Hirst S, Clark PM, Hales CN, Osmond C (1994) Fetal growth and insulin secretion in adult life. Diabetologia 37: 592-596

8. Snoeck A, Remacle C, Reusens B, Hoet JJ (1990) Effect of a low protein diet during pregnancy on the fetal rat endocrine pancreas. Biol Neonate 57: 107-118

9. Van Assche FA, Aerts L (1979) The fetal endocrine pancreas. Contrib Gynecol Obstet 5: 44-57

10. Reusens B, Dahri S, Snoeck A, Bennis-Taleb N (1995) Long term consequences of diabetes and its complications may have a fetal origin: experimental and epidemiological evidence. In: Cowett RM (ed) Diabetes: Nestle Nutrition Workshop Series. Raven Press, New York, pp 187-198

11. Dahri S, Snoeck A, Reusens-Billen B, Remacle C, Hoet JJ (1991) Islet function in offspring of mothers on low-protein diet during gestation. Diabetes 40: 115-120

12. Ozanne SE, Smith GD, Tikerpae J, Hales CN (1996) Altered regulation of hepatic glucose output in the male offspring of protein-malnourished rat dams. Am J Physiol 270: E559-E564

13. Ozanne SE, Wang CL, Coleman N, Smith GD (1996) Altered muscle insulin sensitivity in the male offspring of protein-malnourished rats. Am J Physiol 271: E1128E1134

14. Petry CJ, Ozanne SE, Wang CL, Hales CN (2001) Effects of early protein restriction and adult obesity on rat pancreatic hormone content and glucose tolerance. Horm Metab Res 32: 233-239

15. Hawkins M, Barzilai N, Liu R, Hu M, Chen W, Rossetti L (1997) Role of the glucosamine pathway in fat-induced insulin resistance. J Clin Invest 99: 2173-2182

16. Robinson KA, Sens DA, Buse MG (1993) Pre-exposure to glucosamine induces insulin resistance of glucose transport and glycogen synthesis in isolated rat skeletal muscles. Study of mechanisms in muscle and in rat-1 fibroblasts overexpressing the human insulin receptor. Diabetes 42: 1333-1346

17. Hawkins M, Barzilai N, Chen W, Angelov I, Hu M, Cohen P (1996) Increased hexosamine availability similarly impairs the action of insulin and IGF-1 on glucose disposal. Diabetes 45: 1734-1743

18. Virkamaki A, Daniels MC, Hamalainen S, Utriainen T, McClain D, Yki-Jarvinen H (1997) Activation of the hexosamine pathway by glucosamine in vivo induces insulin resistance in multiple insulin sensitive tissues. Endocrinology 138: 2501-2507

19. Ciaraldi TP, Carter L, Nikoulina S, Mudaliar S, McClain DA, Henry RR (1999) Glucosamine regulation of glucose metabolism in cultured human skeletal muscle cells: divergent effects on glucose transport/phosphorylation and glycogen synthase in non-diabetic and type 2 diabetic subjects. Endocrinology 140: 3971-3980

20. Patti ME, Virkamaki A, Landaker EJ, Kahn CR, YkiJarvinen H (1999) Activation of the hexosamine pathway by glucosamine in vivo induces insulin resistance of early postreceptor insulin signaling events in skeletal muscle. Diabetes 48: 1562-1571
21. Robinson KA, Weinstein ML, Lindenmayer GE, Buse MG (1995) Effects of diabetes and hyperglycemia on the hexosamine synthesis pathway in rat muscle and liver. Diabetes 44: 1438-1446

22. Barker DJP (1997) Maternal nutrition, fetal nutrition, and disease in later life. Nutrition 13: 807-813

23. Barker DJ (1999) The fetal origins of type 2 diabetes mellitus. Ann Intern Med 130: 322-324

24. Hill DJ, Duvillie B (2000) Pancreatic development and adult diabetes. Pediatr Res 48: 269-274

25. Anonymous (1998) Dutch National Food Consumption Survey 1997-1998. Voedingscentrum, The Hague, http://www. voedingscentrum.org

26. Span PN, Powels MJM, Olthaar AJ, Bosch RR, Hermus RMM, Sweep CGJ (2001) Assay for hexosamine pathway intermediates (uridine diphosphate- $\mathrm{N}$-acetyl amino sugars) in small samples of human muscle tissue. Clin Chem 47: 944-946

27. Hoet JJ, Ozanne S, Reussens B (2000) Influences of preand postnatal nutritional exposures on vascular/endocrine systems in animals. Environ Health Perspect 108: 563-568

28. Hales CN, Desai M, Ozanne SE, Crowther NJ (1996) Fishing in the stream of diabetes: from measuring insulin to the control of fetal organogenesis. Biochem Soc Trans 24: 341-350

29. Garofano A, Czernichow P, Breant B (1999) Effects of ageing on beta-cell mass and function in rats malnourished during the perinatal period. Diabetologia 42: 711-718

30. Petrik J, Reusens B, Arany E, Remacle C, Coelho C, Hoet JJ (1999) A low protein diet alters the balance of islet cell replication and apoptosis in the fetal and neonatal rat and is associated with a reduced pancreatic expression of insulin-like growth factor-II. Endocrinology 140: 48614873

31. Bonner-Weir S (2000) Life and death of the pancreatic beta cells. Trends Endocrinol Metab 11: 375-378

32. Slack JMW (1995) Developmental biology of the pancreas. Development 121: 1569-1580

33. Bernard-Kargar C, Ktorza A (2001) Endocrine pancreas plasticity under physiological and pathological conditions. Diabetes 50: S30-S35

34. Weir GC, Laybutt DR, Kaneto H, Bonner-Weir S, Sharma A (2001) Beta-cell adaptation and decompensation during the progression of diabetes. Diabetes 50: S154S159

35. Bertin E, Gangnerau M, Bailbe D, Portha B (1999) Glucose metabolism and B-cell mass in adult offspring of rats protein and/or energy restricted during the last week of pregnancy. Am J Physiol 277: E11-E17

36. Cherif H, Reusens B, Dahri S, Remacle C (2001) A protein restricted diet during pregnancy alters in vitro insulin secretion from islets of fetal wistar rats. J Nutr 131: 15551559

37. Schmitz-Peiffer C, Browne CL, Oakes ND et al. (1997) Alterations on the expression and cellular localization of protein kinase $\mathrm{C}$ isozymes epsilon and theta are associated with insulin resistance in skeletal muscle of the high-fat diet. Diabetes 46: 169-178 